M.E. Bigal, $\mathrm{MD}, \mathrm{PhD}$

T. Kurth, MD, PhD

N. Santanello, MD

D. Buse, $\mathrm{PhD}$

W. Golden, MSci

M. Robbins, MD

R.B. Lipton, MD

Address correspondence and reprint requests to Dr. Marcelo E. Bigal, 1 Merck Dr., PO Box 100 , Whitehouse Station, NJ 08889-0100 marcelo_bigal@merck.com

Editorial, page 622

Supplemental data at www.neurology.org

\section{Migraine and cardiovascular disease}

\section{A population-based study}

$\rightarrow$

\section{ABSTRACT}

Objectives: Although the relationship between migraine and cardiovascular disease (CVD) has been studied, several questions remain unanswered. Herein we contrast the rate of diagnosed CVD as well as of risk factors for CVD in individuals with migraine with and without aura (MA and $\mathrm{MO}$ ) and in controls.

Methods: In this case-control study, migraineurs $(n=6,102)$ and controls $(n=5,243)$ were representative of the adult US population. Headache diagnosis was formally assigned using a validated mailed questionnaire which also obtained details on treatment, comorbidities, and other variables. CVD events were obtained based on self-reported medical diagnosis. Risk factors for CVD and modified Framingham scores were computed.

Results: In unadjusted analyses, migraine overall and MA were associated with myocardial infarction, stroke, and claudication, and MO was associated with myocardial infarction and claudication. Migraineurs were more likely than controls to have a medical diagnosis of diabetes $(12.6 \%$ vs $9.4 \%$, odds ratio [OR] 1.4, 95\% confidence interval [CI] 1.2-1.6), hypertension (33.1\% vs 27.5\%, OR 1.4, $95 \% \mathrm{Cl} 1.3-1.6$ ), and high cholesterol (32.7\% vs 25.6\%, OR 1.4, 95\% Cl 1.3-1.5). Risk was highest in MA, but remained elevated in MO. Framingham scores were significantly higher in $\mathrm{MO}$ and $\mathrm{MA}$ than in controls. After adjustments (gender, age, disability, treatment, CVD risk factors), migraine remained significantly associated with myocardial infarction (OR 2.2, 95\% Cl 1.7-2.8), stroke (OR 1.5, 95\% Cl 1.2-2.1), and claudication (OR 2.69, 95\% Cl 1.98-3.23).

Conclusion: Both migraine with and without aura are associated with cardiovascular disease (CVD) and with risk factors for CVD. However, since our sample size is large, the clinical relevance of the differences is yet to be established. Neurology ${ }^{\circledR} 2010 ; 74: 628-635$

\section{GLOSSARY}

AMPP = American Migraine Prevalence and Prevention; $\mathbf{C l}=$ confidence interval; $\mathbf{C V D}=$ cardiovascular disease; $\mathbf{E T T H}=$ episodic tension type headache; $\mathbf{M A}=$ migraine with aura; $\mathbf{M O}=$ migraine without aura; $\mathbf{O R}=$ odds ratio.

The association between migraine and cardiovascular disease (CVD), including ischemic stroke and subclinical brain lesions, is well established at least for migraine with aura (MA). ${ }^{1-6} \mathrm{MA}$ seems also to be associated with ischemic heart disease, claudication, and cardiovascular mortality. ${ }^{7-9}$ Indeed, it has been speculated that migraine may be a risk factor for atherosclerotic disease in general. ${ }^{10}$

Among the many biologically plausible mechanisms linking migraine and CVD, it has been suggested that persons with MA have a higher prevalence of risk factors for CVD, ${ }^{11}$ as well as with specific genotypes related to CVD. ${ }^{12-14}$ Nonetheless, several questions remain unanswered. First, it is not clear if both MA and MO are risk factors for CVD, or if the association is specific for MA. Second, migraine was assessed based on self-reported medical diagnosis in most studies (although these methods had been validated). 3,7

e-Pub ahead of print on February 10, 2010, at www.neurology.org.

From Scientific Affairs-Neuroscience (M.E.B.), Department of Outcomes Research (N.S.), and Epidemiology (W.G.), Merck Research Laboratories, Whitehouse Station, NJ; Departments of Neurology (M.E.B., D.B., M.R., R.B.L.) and Epidemiology and Population Health (R.B.L.), Albert Einstein College of Medicine, Bronx, NY; Division of Preventive Medicine (T.K.), Department of Medicine, Brigham and Women's Hospital, Harvard Medical School, Boston, MA; and The Montefiore Headache Center (R.B.L.), Bronx, NY.

Study funding: The AMPP was established and initially funded by The National Headache Foundation through a grant from Ortho-McNeil Neurologics, Inc. It is currently cofunded by Merck \& Co. Inc.

Disclosure: Author disclosures are provided at the end of the article. 
As part of the American Migraine Prevalence and Prevention (AMPP) study, 120,000 US households representative of the US population have been followed for 5 years. ${ }^{15-17}$ Accordingly, we took advantage of the accurate characterization of headaches in the AMPP cohort, and resurveyed participants using the same well-validated CVD instruments from the Women's Health Study, ${ }^{7}$ in order to 1) profile cardiovascular risk factors for CVD in migraineurs and controls; 2) ascertain cardiovascular events in individuals with migraine vs controls; and 3) assess the relationship of MA and $\mathrm{MO}$ and CVD in both men and women across a broad range of ages.

METHODS Study population. The AMPP is a longitudinal study of headache sufferers selected from a representative sample of the general population. The AMPP is composed of 2 major phases. In phase 1 (the screening phase) we used a validated self-administered screening questionnaire to identify a nationally representative sample of severe headache sufferers. ${ }^{16}$ The screening questionnaire was mailed in 2004 to a stratified random sample of 120,000 US households, drawn from a 600,000household national panel.

In phase 2 , we selected a random sample of 24,000 headache sufferers for a 5-year follow-up study. Goals of phase 2 included measuring migraine incidence as well as studying the prognosis of migraine and risk factors for progression. ${ }^{18}$

Herein, we report results of our 2008 survey. Because controls had been identified in 2004 but not resurveyed since then, we resurveyed a sample of 10,000 individuals who denied having headaches in 2004. Those subjects who remained free of headaches comprise the control group.

Description of the survey. The questionnaire comprised 82 questions, assessing headache diagnosis, comorbidities, headache-related impact, health-related quality of life, demographics, and other information of interest. The headache module consists of 21 questions for each of up to 3 headache types, validated in a prior study and used each year of the AMPP. ${ }^{19}$

Based on the responses, MA and MO, as well as other episodic headache disorders, were diagnosed according to the Second Edition of the International Classification of Headache..$^{20}$ The survey had been previously shown to have a sensitivity of $100 \%$ and specificity of $82.3 \%$ for the diagnosis of migraine. ${ }^{19}$ As part of the survey, individuals were asked multiple questions on disability (Migraine Disability Assessment Questionnaire), comorbidities, and acute and preventive treatments for migraine, as reported in detail elsewhere. ${ }^{21}$

For controls, the survey consisted of the same validated headache module described above (21 questions), with demographic characterization and assessment of their cardiovascular profile (see below). Controls had no lifetime history of migraine, probable migraine, or chronic daily headaches (we accepted lifetime history of episodic tension type headache [ETTH]) and had experienced no headaches in the past year (without ETTH in the past year).

Assessment of cardiovascular events. We asked about selfreported cardiovascular events (myocardial infarction, stroke, transient ischemic attacks, coronary revascularization, claudication), as well as a medical diagnosis of any of these medical events (e.g., Did a doctor ever tell you that you had a heart attack?). Since results from both forms of ascertainment were very similar, herein we elected to report only on the most conservative survey of medical diagnosis. For each event we asked if the subject ever had the event and then for each event we ascertained the month and year of the event. We followed the same language as well as the same established methods of the Women's Health Study ${ }^{7}$ and of the Physicians' Health Study, ${ }^{8}$ which validated this method by adjudicating CV events through medical record review.

Assessment of cardiovascular profile. In addition to gathering information on established CVD, we obtained information on established risk factors for CVD (e.g., smoking, body mass index, hypertension). We also assessed the cardiovascular profile using the validated modified Framingham Risk score. ${ }^{22}$ This score is calculated based on self-report of blood pressure, cholesterol levels, diabetes, and smoking, and does not include laboratory studies such as lipid profile. In the validation study, the score demonstrated good discrimination (C statistic, 0.763 [men] and 0.793 [women]) and calibration. Specificity was around $84 \%$ and the score correlates exceptionally well with the traditional Framingham Risk assessment. The Framingham risk score is well calibrated to predict absolute risk for first coronary events in populations from the United States. ${ }^{23}$ Other studies also suggest that self-ratings of CVD risk independently predict CVD death. ${ }^{24}$

Analyses. We contrasted control subjects with headache groups on risk of CVD, presence of CVD risk factors, and Framingham risk scores. For all outcomes except Framingham scores, logistic models were employed. For Framingham scores, Gaussian linear models were employed. For all contrasts, control subjects were specified as the reference; thus, odds ratios (ORs) and mean differences reported reflect the difference in odds or means between controls and the focal headache group. These exploratory analyses were stratified by gender, age, race, and body mass index. When pertinent, we also stratified as a function of headache disability (as measured by the MIDAS questionnaire), and by triptan use. For a select subset of risk factors (infarct and stroke) we augmented the stratified analyses by a series of main effect models, adjusting for a set of covariates. Covariates employed included CVD risk factors (diabetes, hypertension, smoking, high cholesterol), as well as body mass index, gender, and age. The SAS system was used for all analyses.

Standard protocol approvals, registrations, and patient consents. The AMPP study, and all its forms, is approved by the Albert Einstein College of Medicine Investigation Review Board, and re-certificated by the institutional review board annually. Participants are volunteers from a representative panel who consented to participate in the research.

RESULTS We surveyed 9,107 individuals from the migraine cohort and 10,000 potentially qualifying controls. Complete responses were obtained for 6,102 with migraine (67\%) and from 5,243 controls (52.4\% response rate). Responders and nonresponders did not significantly differ by demographics. Demographics are presented in table e-1 on the Neurology ${ }^{\circledR}$ Web site at www.neurology.org. Contrasted to controls, migraineurs were more likely to be women $(80.3 \%$ vs $53 \%, p<0.0001)$ and to have 
Table 1 Cardiovascular events as a function of migraine type and of demographics

\begin{tabular}{|c|c|c|c|c|c|c|c|}
\hline & $\begin{array}{l}\text { Control, } \\
\text { n (\%) }\end{array}$ & $\begin{array}{l}\text { Migraine } \\
\text { overall, } \\
\text { n(\%) }\end{array}$ & $\mathrm{OR}^{\mathrm{a}}(95 \% \mathrm{Cl})$ & $\begin{array}{l}\text { Migraine } \\
\text { with aura, } \\
\mathrm{n}(\%)\end{array}$ & $\mathrm{OR}^{\mathrm{a}}(95 \% \mathrm{Cl})$ & $\begin{array}{l}\text { Migraine } \\
\text { without } \\
\text { aura, } \mathrm{n}(\%)\end{array}$ & $\mathrm{OR}^{\mathrm{a}}(95 \% \mathrm{Cl})$ \\
\hline \multicolumn{8}{|l|}{ Heart attack } \\
\hline Overall & $100(1.91)$ & $249(4.08)$ & $2.19(1.73-2.77)$ & $110(5.50)$ & 2.99 (2.27-3.95) & 139 (3.39) & $1.80(1.39-2.34)$ \\
\hline Male & $61(2.47)$ & $92(7.65)$ & $3.27(2.35-4.55)$ & 33 (8.59) & $3.71(2.39-5.74)$ & 59 (7.21) & $3.06(2.12-4.42)$ \\
\hline Female & 39 (1.40) & 157 (3.20) & $2.32(1.63-3.31)$ & $77(4.77)$ & $3.52(2.38-5.19)$ & $80(2.44)$ & $1.75(1.19-2.58)$ \\
\hline $18-29 y$ & $3(0.36)$ & 1 (0.32) & 0.88 (0.09-8.52) & $1(1.30)$ & $3.67(0.38-35.73)$ & $0(0.00)$ & Not available \\
\hline $30-39 y$ & $3(0.28)$ & $10(0.98)$ & 3.55 (0.98-12.95) & $7(2.34)$ & 8.59 (2.21-33.42) & $3(0.42)$ & $1.50(0.30-7.46)$ \\
\hline $40-49 y$ & $6(0.45)$ & 30 (1.88) & $4.25(1.76-10.25)$ & $10(1.80)$ & $4.07(1.47-11.25)$ & 20 (1.92) & $4.35(1.74-10.87)$ \\
\hline $50-59 y$ & 24 (2.42) & $96(5.05)$ & $2.15(1.36-3.38)$ & $51(7.76)$ & $3.40(2.07-5.58)$ & 45 (3.62) & $1.52(0.92-2.51)$ \\
\hline $60-69 y$ & $64(6.46)$ & $112(8.84)$ & $1.40(1.02-1.93)$ & 41 (10.02) & $1.61(1.07-2.43)$ & 71 (8.28) & $1.31(0.92-1.86)$ \\
\hline White & 85 (1.94) & 214 (3.96) & $2.09(1.62-2.69)$ & $88(5.07)$ & $2.70(1.99-3.66)$ & $126(3.44)$ & $1.80(1.36-2.38)$ \\
\hline Black & $12(1.97)$ & $13(3.44)$ & $1.77(0.80-3.93)$ & $7(4.90)$ & $2.56(0.99-6.62)$ & $6(2.55)$ & $1.30(0.48-3.51)$ \\
\hline Other race & $3(1.20)$ & $22(6.79)$ & $5.97(1.77-20.19)$ & 15 (12.61) & 11.83 (3.35-41.72) & $7(3.41)$ & $2.90(0.74-11.36)$ \\
\hline \multicolumn{8}{|l|}{ Stroke } \\
\hline Overall & $66(1.26)$ & $123(2.02)$ & $1.61(1.19-2.18)$ & 77 (3.85) & $3.14(2.25-4.38)$ & $46(1.12)$ & $0.89(0.61-1.30)$ \\
\hline Male & $27(1.10)$ & 25 (2.08) & $1.92(1.11-3.32)$ & $16(4.17)$ & $3.93(2.10-7.36)$ & $9(1.10)$ & $1.00(0.47-2.14)$ \\
\hline Female & $39(1.40)$ & $98(2.00)$ & $1.43(0.99-2.08)$ & 61 (3.78) & $2.76(1.84-4.14)$ & 37 (1.13) & $0.80(0.51-1.26)$ \\
\hline $18-29 y$ & $6(0.71)$ & $2(0.63)$ & $0.88(0.18-4.40)$ & $1(1.30)$ & $1.83(0.22-15.39)$ & $1(0.42)$ & $0.58(0.07-4.85)$ \\
\hline $30-39 y$ & $5(0.46)$ & $8(0.79)$ & $1.70(0.55-5.21)$ & $5(1.67)$ & 3.65 (1.05-12.69) & $3(0.42)$ & $0.90(0.21-3.77)$ \\
\hline $40-49 y$ & $11(0.82)$ & 19 (1.19) & $1.45(0.69-3.06)$ & $13(2.33)$ & $2.89(1.29-6.49)$ & $6(0.58)$ & $0.70(0.26-1.90)$ \\
\hline $50-59 y$ & $10(1.01)$ & 49 (2.58) & $2.60(1.31-5.16)$ & 33 (5.02) & $5.20(2.54-10.62)$ & $16(1.29)$ & $1.28(0.58-2.84)$ \\
\hline $60-69 y$ & 34 (3.43) & 45 (3.55) & $1.04(0.66-1.63)$ & $25(6.11)$ & $1.83(1.08-3.11)$ & 20 (2.33) & $0.67(0.38-1.18)$ \\
\hline White & $43(0.98)$ & $101(1.87)$ & $1.92(1.34-2.76)$ & $62(3.57)$ & $3.74(2.52-5.54)$ & 39 (1.06) & $1.09(0.70-1.68)$ \\
\hline Black & 19 (3.12) & $10(2.65)$ & $0.84(0.39-1.83)$ & $6(4.20)$ & $1.36(0.53-3.47)$ & $4(1.70)$ & $0.54(0.18-1.60)$ \\
\hline Other race & $4(1.61)$ & 12 (3.70) & $2.36(0.75-7.39)$ & $9(7.56)$ & 5.01 (1.51-16.62) & $3(1.46)$ & $0.91(0.20-4.11)$ \\
\hline \multicolumn{8}{|l|}{ Claudication } \\
\hline Overall & $48(0.92)$ & $157(2.57)$ & $2.86(2.06-3.96)$ & $83(4.15)$ & 4.69 (3.27-6.72) & $74(1.80)$ & $1.99(1.38-2.87)$ \\
\hline Male & $19(0.77)$ & 38 (3.16) & $4.20(2.41-7.32)$ & $17(4.43)$ & 5.96 (3.07-11.58) & $21(2.57)$ & $3.39(1.81-6.34)$ \\
\hline Female & $29(1.04)$ & 119 (2.43) & $2.36(1.57-3.55)$ & $66(4.09)$ & $4.04(2.60-6.28)$ & $53(1.61)$ & $1.55(0.99-2.45)$ \\
\hline $18-29 y$ & $1(0.12)$ & $1(0.32)$ & $0.66(0.17-42.58)$ & $0(0.00)$ & Not available & $1(0.42)$ & $3.51(0.22-56.33)$ \\
\hline $30-39 y$ & $2(0.19)$ & 11 (1.08) & $5.88(1.30-26.58)$ & $4(1.34)$ & 7.29 (1.33-40.02) & $7(0.97)$ & $5.29(1.10-25.53)$ \\
\hline $40-49 y$ & $6(0.45)$ & 21 (1.31) & $2.96(1.19-7.35)$ & $14(2.51)$ & $5.74(2.19-15.01)$ & $7(0.67)$ & $1.50(0.50-4.49)$ \\
\hline $50-59 y$ & $10(1.01)$ & 64 (3.37) & $3.43(1.75-6.70)$ & 38 (5.78) & $6.03(2.99-12.20)$ & 26 (2.09) & $2.10(1.01-4.38)$ \\
\hline $60-69 y$ & 29 (2.93) & $60(4.74)$ & $1.65(1.05-2.59)$ & $27(6.60)$ & $2.34(1.37-4.01)$ & 33 (3.85) & $1.33(0.80-2.20)$ \\
\hline White & $33(0.75)$ & $128(2.37)$ & $3.20(2.18-4.70)$ & $67(3.86)$ & $5.29(3.47-8.06)$ & 61 (1.67) & $2.23(1.46-3.42)$ \\
\hline Black & 14 (2.30) & $17(4.50)$ & $2.00(0.97-4.11)$ & $9(6.29)$ & 2.85 (1.21-6.73) & $8(3.40)$ & $1.50(0.62-3.62)$ \\
\hline Other race & $1(0.40)$ & $12(3.70)$ & $9.54(1.23-73.86)$ & $7(5.88)$ & $15.50(1.88-127.48)$ & $5(2.44)$ & $6.20(0.72-53.50)$ \\
\hline
\end{tabular}

Abbreviations: $\mathrm{Cl}=$ confidence interval; $\mathrm{OR}=$ odds ratio. a All ORs are vs control.

lower income $(p<0.001)$. Controls were younger $($ median age $=20.4$ vs 24.0) $(p<0.01)$.

Cardiovascular events: Univariate associations. Table 1 displays the rates of which migraineurs and controls had a medical diagnosis of cardiovascular events. For migraine overall and for MA, rates were higher for heart attack, stroke, and claudication. For $\mathrm{MO}$, rates were higher for heart attack and claudica- tion, but not for stroke. Rates were higher in MA than in MO.

For myocardial infarction, overall migraine was associated with significantly increased risk relative to controls for all ages older than 39 years. Myocardial infarction occurred in $1.9 \%$ of controls and $4.1 \%$ of migraineurs (OR 2.2, 95\% confidence interval [CI] 1.7-2.7). ORs were higher for both 30-39 years and 
$40-49$ years (3.5 and 4.2) age groups and decreased (although remaining significantly elevated) thereafter. Rates were significantly increased in men (OR 3.3, 95\% CI 2.4-4.6) and women (OR 2.3, 95\% CI 1.6-3.3). Rates were significantly increased in white subjects (OR 2.1, 95\% CI 1.6-2.7) and nonsignificantly increased in black subjects. Ratios were further increased in MA relative to controls: men $=3.7$ (2.4-5.7); women $=3.5(2.4-5.2)$. Risk was highest in those 30-39 years (OR 8.6, 95\% CI 2.2-33.4) and $40-49$ years (OR 4.1, 95\% CI 1.5-11.2). Risk was also elevated in $\mathrm{MO}$ relative to controls: overall (OR 1.8, 95\% CI 1.4-2.3) and in men (OR 3.1, 95\% CI 2.1-4.4) and women (OR 1.7, 95\% CI 1.2-2.6). Highest risk was in women and in those aged $40-49$ years (OR 4.4, 95\% CI 1.7-10.9).

Figure 1 Cardiovascular events and migraine

\section{A Migraine with aura}

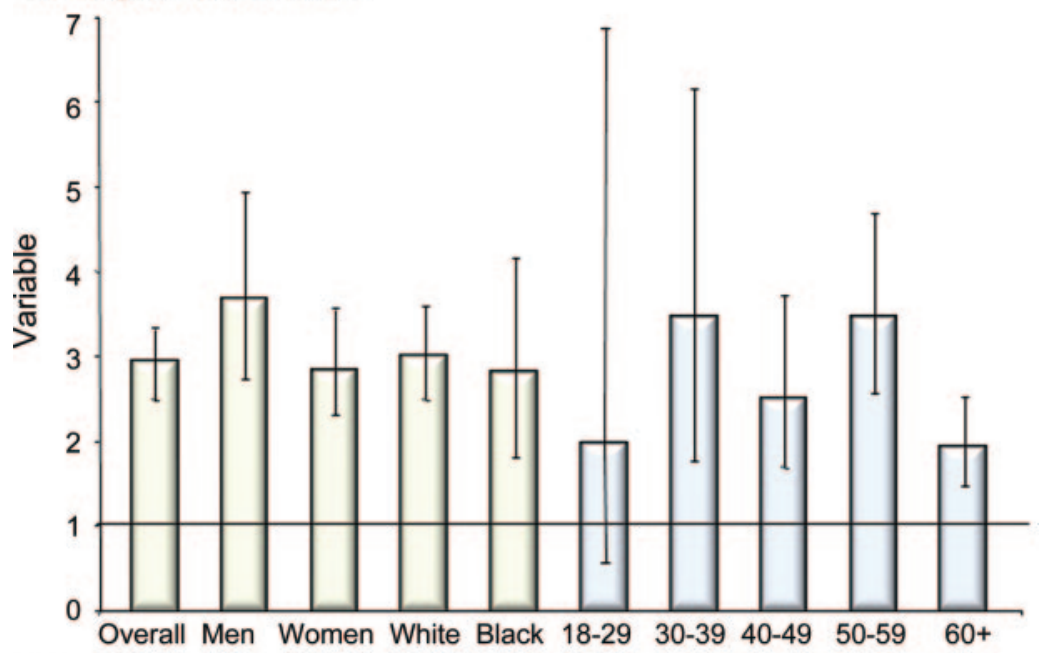

\section{B Migraine without aura}

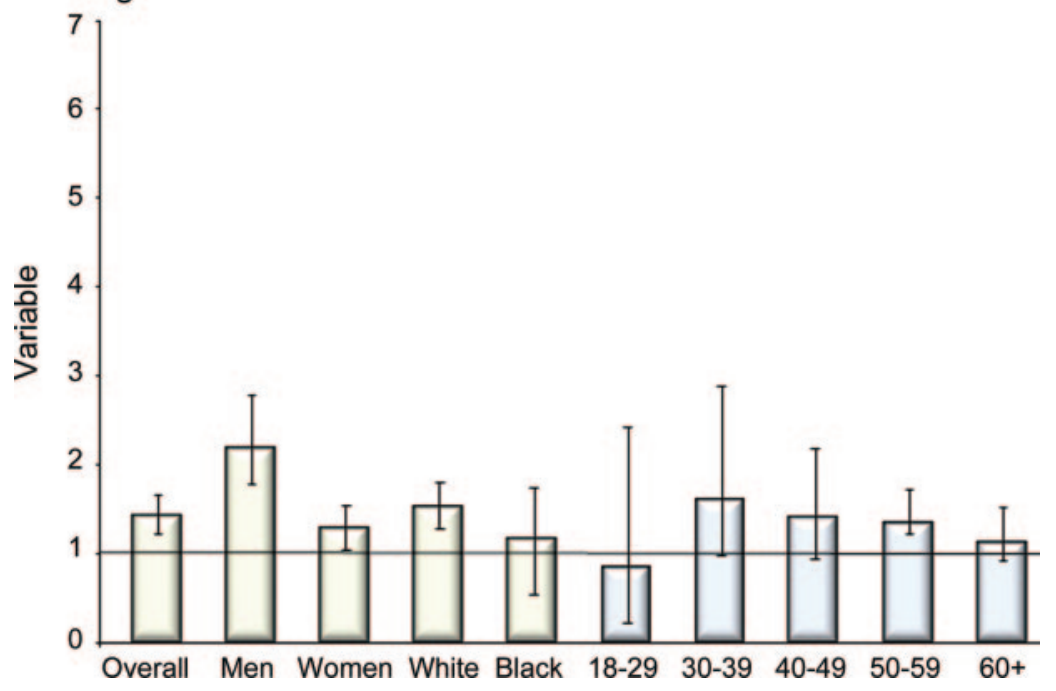

Odds ratios of reporting any cardiovascular event in individuals with migraine with aura (A) and migraine without aura (B). Bars represent the odds ratios and whiskers represent the confidence intervals.
Stroke occurred in $1.2 \%$ of the controls and $2.1 \%$ of the migraineurs (OR 1.61, 95\% CI 1.2-2.2). Rates were $3.9 \%$ in MA (OR 3.1, 95\% CI 2.2-4.4) and $1.12 \%$ of MO (OR $0.9,95 \%$ CI $0.6-1.3$ ). MA rates were elevated for both genders and all ages older than 30. For MO, risk was not significantly different (for either gender or any age group). However, numbers of events were small, making comparisons in some of these subgroups difficult.

Finally, for claudication, risk was increased in migraine overall $(2.57 \%$ vs $0.9 \%$, OR $2.9,95 \% \mathrm{CI}$ 2.1-3.9) and in both migraine subtypes. In MA, risk was significantly increased in both genders, races, and all ages older than 30 . For MO, risk was significantly elevated in men and in white subjects, and tended to be significant in other categories (table 1).

Figure 1 displays the odds of reporting any of the possible cardiovascular events captured in our study, in MA and MO, relative to controls. As displayed, the magnitude of the association is higher for MA, but also significant for MO for men and white subjects, although not for the other categories.

Risk factors for cardiovascular disease. Table e- 2 contrasts the rates of known cardiovascular risk factors as a function of migraine status, stratified by demographics. Overall, migraineurs were more likely than controls to have a medical diagnosis of diabetes (12.6\% vs $9.4 \%$, OR $1.4,95 \%$ CI $1.2-1.6)$, hypertension $(33.1 \%$ vs $27.5 \%$, OR $1.4,95 \%$ CI $1.3-$ 1.6), and high cholesterol (32.7\% vs $25.6 \%$, OR 1.4 , 95\% CI 1.3-1.5). Although they were significantly more likely to smoke, differences are small, and the significance likely reflects our large sample size.

MA was significantly associated with all risk factors. $\mathrm{MO}$ was significantly associated with diabetes, hypertension, and high cholesterol, but not with smoking. Although the magnitude of the association was higher for MA than for MO (table e-2), the differences were not as broad as seen for CVD, as detailed in table 1.

Figure 2 displays the odds of reporting at least 2 of the 4 assessed risk factors, in MA and MO, relative to controls. Both individuals with MA and MO were significantly more likely to have more than one cardiovascular risk factor, relative to controls, for most demographic categories.

Assessment of cardiovascular risk: Framingham scores. Figure 3 displays the Framingham scores for migraine overall, MA, and $\mathrm{MO}$, as well as by gender and age. Overall, risk scores were significantly higher for all migraineurs (mean 10.7, SD 5.4), MA (11.0, 5.4), and $\mathrm{MO}(10.6,5.4)$ as compared to controls $(8.5,6.1)(p<0.001$ for all comparisons with controls). Scores were significantly higher in migraineurs 
Figure 2 Cardiovascular risk and migraine

\section{A Migraine with aura}

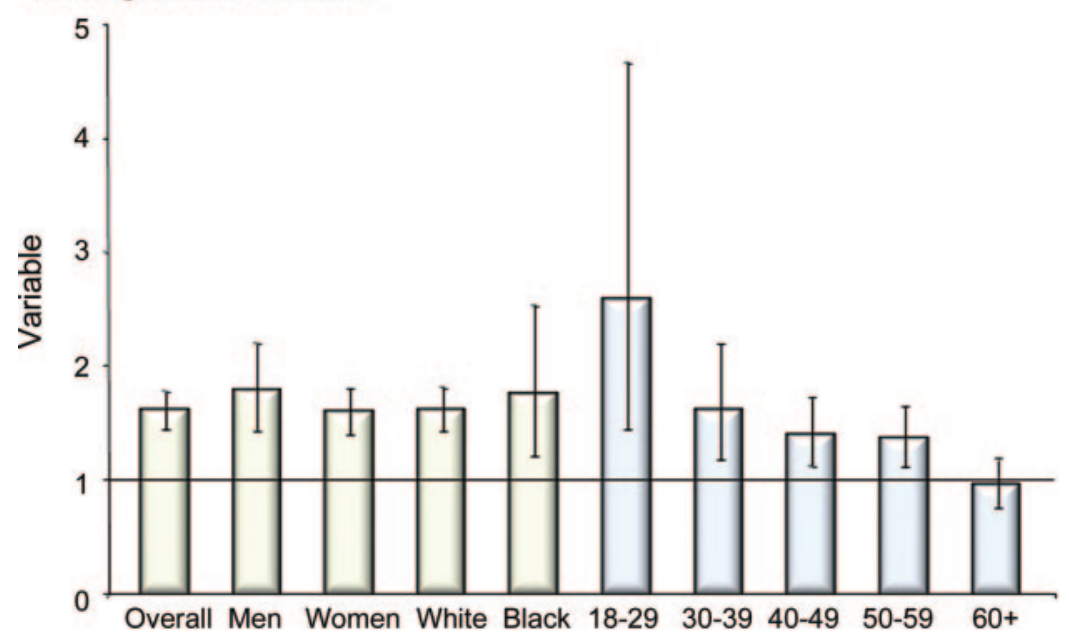

\section{B Migraine without aura}

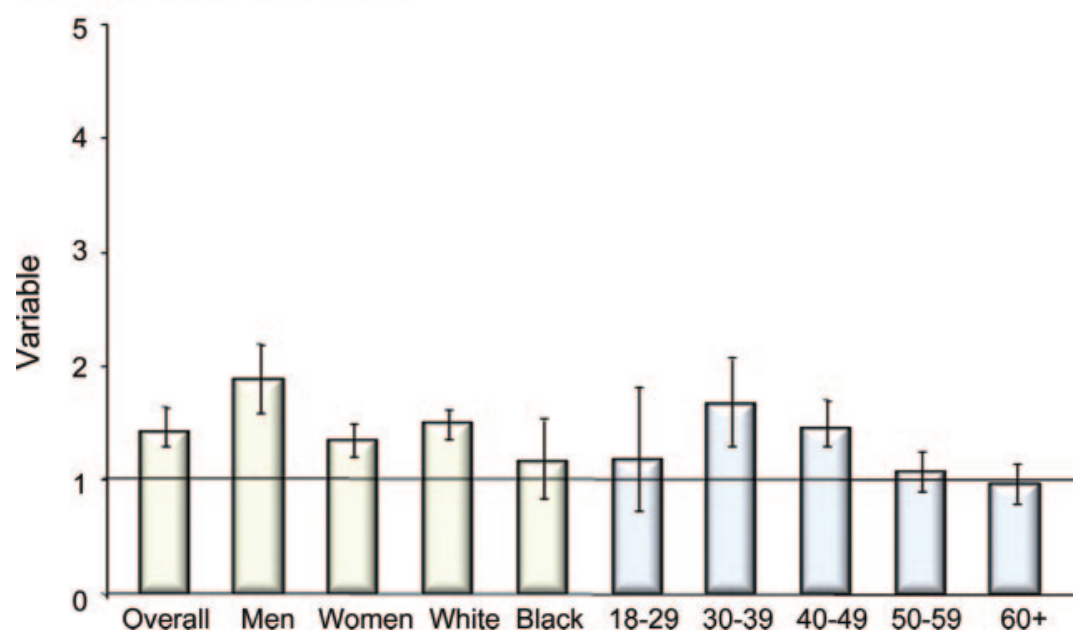

Odds ratios of reporting at least 2 risk factors for cardiovascular events in individuals with migraine with aura $(A)$ and migraine without aura $(B)$. Bars represent the odds ratios and whiskers represent the confidence intervals.

of both genders (overall and for MO and MA). Scores were numerically higher for all age groups younger than 70 years. Scores were significantly higher for migraineurs in all age ranges from 30 to 59 years.

Multivariate analyses. Because migraine was associated with both CVD and risk factors for CVD, and since some medications used to treat migraine are vasoconstrictive, in our multivariate models we tested main effects after adjusting for gender, age, disability, and triptan use, as well as for the CVD risk factors assessed in our study (diabetes, hypertension, smoking, and high cholesterol). Overall migraine remained significantly associated with myocardial infarction (OR 2.2, 95\% CI 1.7-2.8), stroke (OR 1.5, 95\% CI 1.22.1 ), and claudication (OR 2.69, 95\% CI 1.98-3.23). MA was significantly associated with the 3 outcomes.
MO remained associated with myocardial infarct and claudication but not stroke (table 2).

DISCUSSION The association between migraine and cardiovascular events has been explored in several studies. For TIA, ischemic stroke, and subclinical lesions in the brain, the association with MA has been demonstrated in case-control and crosssectional studies, summarized in meta-analyses, ${ }^{25-27}$ and demonstrated in large longitudinal studies. $3,4,28$

Due to the association between migraine (mostly MA) and ischemic stroke, it is of interest whether migraine is similarly associated with coronary heart disease as well. Although some studies yielded negative results, ${ }^{29}$ case reports $^{30}$ and cohort studies ${ }^{9}$ found an association between migraine and chest pain, and with ischemic electrocardiographic changes. ${ }^{31}$ Furthermore, 3 recent population studies supported the relationship between MA and coronary disease. ${ }^{3,7-9}$ Finally, subclinical markers of vascular disease have also been suggested to be altered in patients with migraine. ${ }^{10}$

Some of our findings confirm the results of prior population studies, while some of them add information to what has been largely seen as controversial. Among the confirmatory components, we found that $\mathrm{MA}$ is a risk factor for not only stroke, but also for heart attack and claudication, as well as for CVD risk factors (especially diabetes, hypertension, and high cholesterol). Our study clearly suggests that $\mathrm{MO}$ is also associated with heart attack (but not stroke), and with risk factors for cardiovascular events. For established events, the magnitude of risk was inferior to MA, but existent. For risk factors for cardiovascular events, the difference between $\mathrm{MO}$ and MA was smaller. Individuals with $\mathrm{MO}$, as individuals with MA, had elevated cardiovascular risk, as assessed by the modified Framingham score, when compared to controls.

The mechanisms that link migraine to ischemic vascular disease remain unclear and are likely to be complex, and the topic was reviewed elsewhere. ${ }^{32}$ For example, cortical spreading depression, the presumed substrate of aura, may directly predispose to brain lesions, and that would explain why MA is consistently demonstrated as a risk factor for cerebral ischemia. For heart attack and claudication, other factors should play a role (e.g., migraine being associated with overall atherosclerosis, ${ }^{10}$ or being comorbid with risk factors for $\mathrm{CVD}^{11}$ ). Understanding the causal nature and the pathophysiology of the association is fundamental. Nonetheless, although our knowledge of the mechanisms of the association is limited, when put in the context of the available evidence, our findings suggest that a change in the conceptual paradigm of migraine may be of importance. 


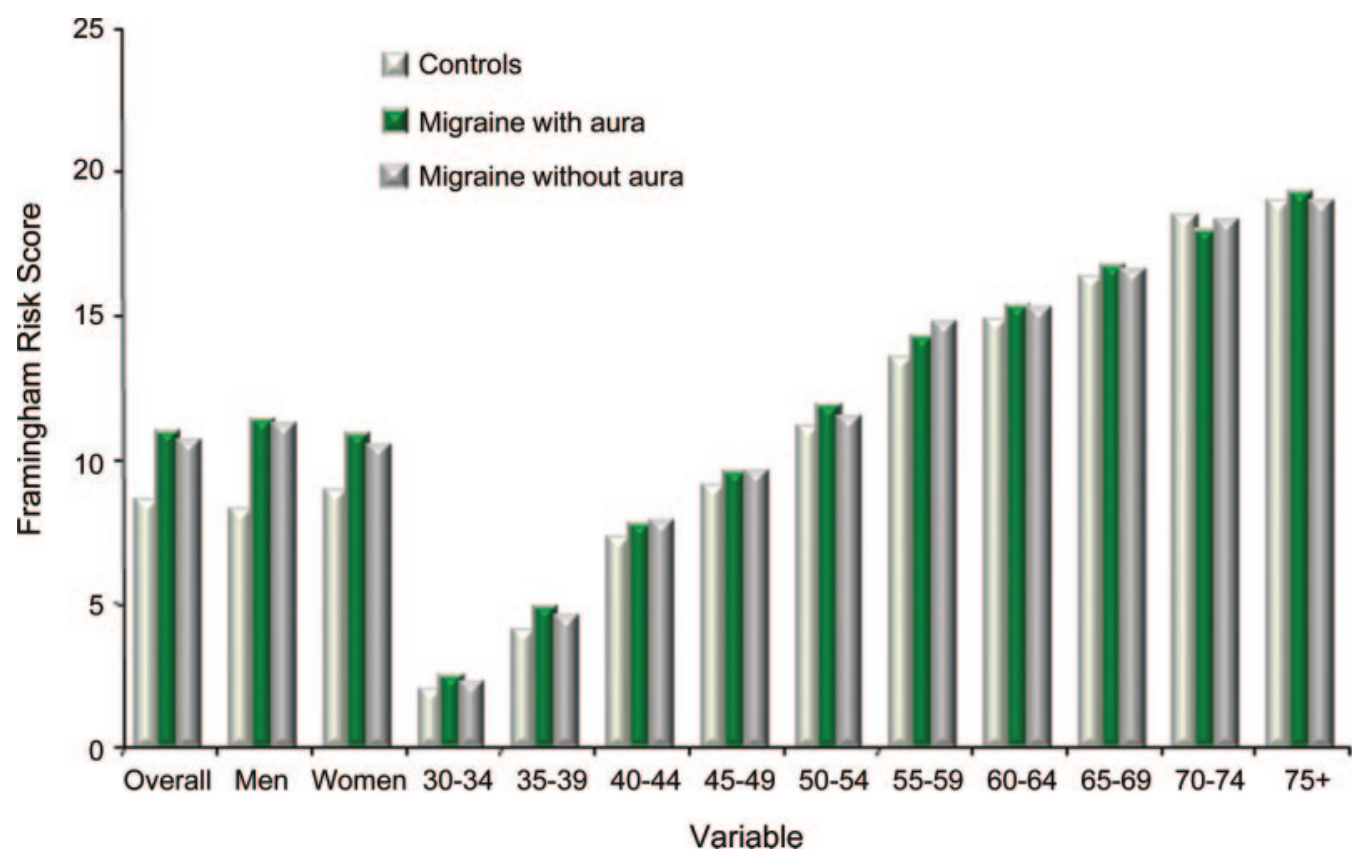

Mean Framingham scores of participants as a function of their headache status and of demographics. Stratification is by age in years.

It had been suggested that only patients with MA were at increased risk for CVD and therefore, the vast majority of patients (especially those with $\mathrm{MO}$ ) should be reassured. ${ }^{33}$ We agree that most migraineurs (with or without aura) should be reassured. Nonetheless, the risk is existent. Future studies should focus on defining migraineurs at especially higher risk. Examples include assessing the importance of headache frequency and severity, frequency of auras, as well as the cumulative importance of multiple risk factors and the relative risk of migraine vs other risk factors. Second, it is important to assess how migraine treatment modifies the risk. For example, if frequency of auras and of headaches increases the risk of CVD, migraine prophylaxis should be associated with a decreased risk. Alternatively, the relevance of acute treatment in either reducing or increasing the risk should be estimated, especially considering that some antiinflammatory medications

\begin{tabular}{|llll|}
\hline Table 2 & $\begin{array}{l}\text { Main effect of migraine and of migraine subtypes in CVD outcomes } \\
\text { after adjustments }\end{array}$ \\
\hline & $\begin{array}{l}\text { Migraine vs control, } \\
\text { OR (95\% Cl) }\end{array}$ & $\begin{array}{l}\text { MA vs control, } \\
\text { OR (95\% Cl) }\end{array}$ & $\begin{array}{l}\text { MO vs control, } \\
\text { OR (95\% Cl) }\end{array}$ \\
$\begin{array}{l}\text { CVD outcome } \\
\begin{array}{l}\text { Myocardial } \\
\text { infarction }\end{array}\end{array}$ & $2.16(1.70-2.76)$ & $2.86(2.14-3.82)$ & $1.85(1.41-2.42)$ \\
\hline $\begin{array}{l}\text { Stroke } \\
\text { Claudication }\end{array}$ & $1.54(1.16-2.05)$ & $2.78(2.02-3.84)$ & $0.97(0.69-1.36)$ \\
\hline
\end{tabular}

Abbreviations: $\mathrm{Cl}=$ confidence interval; $\mathrm{CVD}=$ cardiovascular disease; $\mathrm{MA}=$ migraine with aura; $\mathrm{MO}$ = migraine without aura; $\mathrm{OR}$ = odds ratio.

aSee Methods for adjustments and list of covariates. are associated with increased cardiovascular risk, ${ }^{34}$ and that compounds with ergotamine are vasoconstrictive. ${ }^{35}$ Furthermore, the importance of cardioprotective medications in the context of migraine treatment should be assessed. ${ }^{36}$ Finally, based on the findings, clinicians should have heightened vigilance for modifiable cardiovascular risk factors in migraineurs, such as obesity, hypertension, hyperlipidemia, and diabetes. Furthermore, components of the metabolic syndrome are comorbid with migraine. ${ }^{37}$

Our study has limitations. First, headache diagnoses were based on questionnaires and not on in-person clinical assessment. Though our questionnaires were well-validated and have great sensitivity and specificity, ${ }^{38}$ some degree of diagnostic error is likely. However, these errors would unlikely account for our strikingly positive findings. Second, assessment of cardiovascular events and risk factors were also based on self-report of medical diagnosis. Again, these methods have been validated through adjudication of events and are widely accepted., ${ }^{3,22}$ Nonetheless, as a preparation for future steps of our study, we are also conducting adjudication of cardiovascular events, in order to revalidate the method. While this step is not finished, caution is suggested. In addition, many factors that could add to the risk of CVD were not collected, mostly due to limitations in the length of the questionnaire survey. Most notably, we have not modeled the influence of using contraceptive pills or hormone replacement therapy in our findings. Nonetheless, since our results remained strik- 
ingly positive for men, and unless a differential use of contraceptive medications or hormone replacement therapy between migraineurs and controls exists, the potential for bias should not be high. Also, some of the comparisons made, particularly the subgroup comparisons, involved a small number of events and therefore some findings for these subgroup analyses may not be reliable. Furthermore, since our sample size is large, some of the statistically significant differences may not be clinically relevant. Finally, we acknowledge the limitation that individuals with risk factors for CVD may visit a physician more frequently than those without, with a correspondent higher chance of being diagnosed with migraine.

Strengths of our study include the meticulous assessment of headache features, the use of very wellvalidated instruments, the good characterization of the cohort, the confidence about lack of headaches in controls (since they were surveyed twice: in 2004 and again for this study), and the robustness of our sample size.

Both MA and MO are associated with CVD and with risk factors for CVD. Providers should be aware of this association in order to properly identify individuals at particularly high risk, as well as in order to plan treatment that targets not only migraine, but the complications potentially associated with migraine.

\section{DISCLOSURE}

Dr. Bigal has served on scientific advisory boards for Merck \& Co. Inc., GlaxoSmithKline, AstraZeneca, and OMP; serves as Co-editor of the Abstract Section of Headache; has served on speakers' bureaus for and received speaker honoraria from Merck \& Co. Inc., Pfizer Inc., and OMP; is a full-time employee of and holds stock and stock options in Merck \& Co. Inc.; and has received research support from the National Headache Foundation and the American Headache Society. Dr. Kurth has received funding for travel from the Restless Legs Syndrome Foundation; serves as a consultant to i3 Drug Safety and World Health Information Science Consultants, LLC; has received honoraria from Genzyme Corporation, Merck Serono, and Pfizer Inc. for educational lectures; and has received research support from McNeil Consumer \& Specialty Pharmaceuticals, Merck Serono, Wyeth, the NIH [HL091880-01 (PI) and NS061836-01 (PI))], the French National Research Agency, and the Migraine Research Foundation. Dr. Santanello serves as a reviewer for foundation grants and fellowship awards for PhRMA Foundation; is a full-time employee (Vice President of Epidemiology) of and holds stock and stock option in Merck \& Co., Inc.; and in his position as Vice President of Epidemiology has acted as a witness in legal proceedings. Dr. Buse has served on a scientific advisory board for ENDO Pharmaceuticals. Dr. Golden is a full-time employee of and holds stock option in Merck \& Co. Inc. Dr. Robbins received a Kirschtein National Service Research Award (training grant in geriatrics). Dr. Lipton serves/has served on scientific advisory boards for and received funding for travel from Bayer Schering Pharma, Merck Serono, GlaxoSmithKline, Endo Pharmaceuticals, Kowa Pharmaceuticals America, Inc., Allergan, Inc., Neuralieve Inc., OrthoMcNeil-Janssen Pharmaceuticals, Inc.; has received funding for travel from the American Headache Society and the Diamond Headache Center; serves as Associate Editor of Cephalalgia and on the editorial boards of Neurology ${ }^{\circledR}$ and Headache; receives royalties from publishing Headache in Clinical Practice (Isis Medical Media, 2002), Headache in Primary Care (Isis Medical Media, 1999), Wolff's Headache (Oxford University Press, 2001, 2008), Managing Migraine: A Physician's Guide (BC Decker, 2008), and Managing Migraine: A Patient's Guide (BC Decker, 2008); has re- ceived speaker honoraria from the National Headache Foundation, the University of Oklahoma, the American Academy of Neurology, the Annenberg Foundation, Merck Serono, GlaxoSmithKline, and Coherex Medical; receives research support from the American Headache Society, National Headache Foundation, the Migraine Research Foundation, and the NIH [PO1AG03949 (Program Director, Project Leader), PO1AG027734 (Project Leader), RO1AG25119 (Co-I), K23AG030857 (Co-Mentor), K23NS05140901A1(Co-Mentor), and K23NS47256 (Mentor)]; and holds stock options in Minster Pharmaceuticals plc.

Received May 31, 2009. Accepted in final form October 9, 2009.

\section{REFERENCES}

1. Elliott D. Migraine and stroke: current perspectives. Neurol Res 2008;30:801-812.

2. Kruit MC, van Buchem MA, Hofman PA, et al. Migraine as a risk factor for subclinical brain lesions. JAMA 2004; 291:427-434.

3. Kurth T, Slomke MA, Kase CS, et al. Migraine, headache, and the risk of stroke in women: a prospective study. Neurology 2005;64:1020-1026.

4. MacClellan LR, Mitchell BD, Cole JW, et al. Familial aggregation of ischemic stroke in young women: the Stroke Prevention in Young Women Study. Genet Epidemiol 2006;30:602-608.

5. Kruit MC, Launer LJ, Ferrari MD, van Buchem MA. Brain stem and cerebellar hyperintense lesions in migraine. Stroke 2006;37:1109-1112.

6. Kurth T, Diener HC. Current views of the risk of stroke for migraine with and migraine without aura. Curr Pain Headache Rep 2006;10:214-220.

7. Kurth T, Gaziano JM, Cook NR, Logroscino G, Diener $\mathrm{HC}$, Buring JE. Migraine and risk of cardiovascular disease in women. JAMA 2006;296:283-291.

8. Kurth T, Gaziano JM, Cook NR, et al. Migraine and risk of cardiovascular disease in men. Arch Intern Med 2007; 167:795-801.

9. Rose KM, Carson AP, Sanford CP, et al. Migraine and other headaches: associations with Rose angina and coronary heart disease. Neurology 2004;63:2233-2239.

10. Rose KM, Wong TY, Carson AP, Couper DJ, Klein R, Sharrett AR. Migraine and retinal microvascular abnormalities: the Atherosclerosis Risk in Communities Study. Neurology 2007;68:1694-1700.

11. Scher AI, Terwindt GM, Picavet HS, Verschuren WM, Ferrari MD, Launer LJ. Cardiovascular risk factors and migraine: the GEM population-based study. Neurology 2005;64:614-620.

12. Scher AI, Terwindt GM, Verschuren WM, et al. Migraine and MTHFR C677T genotype in a population-based sample. Ann Neurol 2006;59:372-375.

13. Schürks M, Zee RY, Buring JE, Kurth T. Polymorphisms in the renin-angiotensin system and migraine in women. Headache 2009;49:292-299.

14. Schürks M, Zee RY, Buring JE, Kurth T. Interrelationships among the MTHFR 677C $>\mathrm{T}$ polymorphism, migraine, and cardiovascular disease. Neurology 2008;71: 505-513.

15. Lipton RB, Bigal ME, Diamond M, Freitag F, Reed ML, Stewart WF. Migraine prevalence, disease burden, and the need for preventive therapy. Neurology 2007;68:343-349.

16. Stewart WF RM, Bigal ME, Lipton RB. Lifetime migraine incidence: results from the American Migraine Prevalence and Prevention study. Headache 2005;46:52. 
17. Diamond S, Bigal ME, Silberstein S, Loder E, Reed M, Lipton RB. Patterns of diagnosis and acute and preventive treatment for migraine in the United States: results from the American Migraine Prevalence and Prevention study. Headache 2007;47:355-363.

18. Bigal ME, Lipton RB. Excessive acute migraine medication use and migraine progression. Neurology 2008;71: 1821-1828.

19. Lipton RB, Stewart WF, Diamond S, Diamond ML, Reed M. Prevalence and burden of migraine in the United States: data from the American Migraine Study II. Headache 2001;41:646-657.

20. The International Classification of Headache Disorders, 2nd edition. Cephalalgia 2004;24(suppl 1):1-149.

21. Bigal ME, Serrano D, Reed M, Lipton RB. Chronic migraine in the population: burden, diagnosis, and satisfaction with treatment. Neurology 2008;71:559-566.

22. D'Agostino RB Sr, Vasan RS, Pencina MJ, et al. General cardiovascular risk profile for use in primary care: the Framingham Heart Study. Circulation 2008;117:743-753.

23. Lloyd-Jones DM, Wilson PW, Larson MG, et al. Framingham risk score and prediction of lifetime risk for coronary heart disease. Am J Cardiol 2004;94:20-24.

24. Gramling R, Klein W, Roberts M, Waring ME, Gramling D, Eaton CB. Self-rated cardiovascular risk and 15-year cardiovascular mortality. Ann Fam Med 2008;6:302-306.

25. Etminan M, Takkouche B, Isorna FC, Samii A. Risk of ischaemic stroke in people with migraine: systematic review and meta-analysis of observational studies. BMJ 2005;330:63.

26. Buring JE, Hebert P, Romero J, et al. Migraine and subsequent risk of stroke in the Physicians' Health Study. Arch Neurol 1995;52:129-134.

27. Diener HC, Kurth T. Is migraine a risk factor for stroke? Neurology 2005;64:1496-1497.
28. Porter A, Gladstone JP, Dodick DW. Migraine and white matter hyperintensities. Curr Pain Headache Rep 2005;9: 289-293.

29. Rosamond W. Are migraine and coronary heart disease associated? An epidemiologic review. Headache 2004;44 suppl 1:S5-S12.

30. Wayne VS. A possible relationship between migraine and coronary artery spasm. Aust NZ J Med 1986;16:708-710.

31. Uyarel H, Erden I, Cam N. Acute migraine attack, anginalike chest pain with documented ST-segment elevation and slow coronary flow. Acta Cardiol 2005;60:221-223.

32. Bigal ME, Kurth T, Hu H, Santanello N, Lipton RB. Migraine and cardiovascular disease: possible mechanisms of interaction. Neurology 2009;72:1864-1871.

33. Bigal M, Kurth T, Hu H, Santanello N, Lipton R. Migraine and cardiovascular disease: possible mechanisms of interaction. Neurology 2009;72:1864-1871.

34. Chan AT, Manson JE, Albert CM, et al. Nonsteroidal antiinflammatory drugs, acetaminophen, and the risk of cardiovascular events. Circulation 2006;113:15781587.

35. Hargreaves RJ. Pharmacology and potential mechanisms of action of rizatriptan. Cephalalgia 2000;20 suppl 1:2-9.

36. Bigal ME, Sheftell FD, Tepper SJ, Rapoport AM. Migraine and silent infarcts. Are we making the proper decisions? Cephalalgia 2006;26:629-630.

37. Cavestro C, Rosatello A, Micca G, et al. Insulin metabolism is altered in migraineurs: a new pathogenic mechanism for migraine? Headache 2007;47:1436-1442.

38. Lipton RB, Stewart WF, Simon D. Medical consultation for migraine: results from the American Migraine Study. Headache 1998;38:87-96.

\section{Pre-order the AAN 2010 Virtual Annual Meeting and Save up to $\$ \mathbf{8 0 0}$}

The 2010 Virtual Annual Meeting suite of products now brings you high-quality education programming and the latest science-all from the convenience and comfort of your home, office, car, or virtually anywhere.

\section{$N E W$ ! Special two- and three-pack pricing available:}

- Virtual Annual Meeting 3-Pack (save up to $\$ 800^{*}$ )

- Virtual Annual Meeting 2-Pack (save up to $\$ 650^{*}$ )

Or purchase them individually:

- Syllabi on CD (save up to $\$ 200^{*}$ )

- Webcasts-On-Demand and on DVD (save up to $\$ 450^{*}$ )

- MP3-On-Demand and on DVD (save up to $\$ 150^{*}$ )

- Practice CD (save up to $\$ 50^{*}$ )

Order by March 10 to save up to $\$ 800$ : Visit www.ann.com/vam today!

*Savings based on AAN member pre-meeting pricing vs list pricing. 